early in DNA damage response and regulate RAP80 localization.

Many cell cycle checkpoint proteins, including ATM, Chk2, BRCA1, and p53, play critical roles in the maintenance of genomic stability. Their mutation often results in increased tumor incidence, highlighting the importance of the integrity of DNA damage pathways in tumor suppression. As a BRCA1-associated protein involved in DNA damage checkpoint control, RAP80 may also function as a tumor suppressor and be dysregulated or mutated in human patients. Future genetic studies will allow us to test this possibility.

\section{References and Notes}

1. B. B. Zhou, S. J. Elledge, Nature 408, 433 (2000).

2. J. Rouse, S. P. Jackson, Science 297, 547 (2002).

3. W. C. Hahn, R. A. Weinberg, N. Engl. J. Med. 347, 1593 (2002).

4. T. T. Su, Annu. Rev. Genet. 40, 187 (2006).

5. F. J. Couch et al., N. Engl. J. Med. 336, 1409 (1997).
6. D. Ford et al., Am. J. Hum. Genet. 62, 676 (1998).

7. R. Hashizume et al., J. Biol. Chem. 276, 14537 (2001).

8. A. Chen, F. E. Kleiman, ]. L. Manley, T. Ouchi, Z. Q. Pan, J. Biol. Chem. 277, 22085 (2002).

9. X. Yu, J. Chen, Mol. Cell. Biol. 24, 9478 (2004)

10. S. B. Cantor et al., Cell 105, 149 (2001).

11. Z. Yan, Y. S. Kim, A. M. Jetten, J. Biol. Chem. 277, 32379 (2002).

12. Materials and methods are available as supporting material on Science Online.

13. S. Hirano et al., Nat. Struct. Mol. Biol. 13, 272 (2006).

14. Single-letter abbreviations for the amino acid residues are as follows: A, Ala; C, Cys; D, Asp; E, Glu; F, Phe; G, Gly; H, His; I, Ile; K, Lys; L, Leu; M, Met; N, Asn; P, Pro; Q, Gln; R, Arg; S, Ser; T, Thr; V, Val; W, Trp; and Y, Tyr.

15. C. X. Deng, S. G. Brodie, Bioessays 22, 728 (2000).

16. B. Xu, S. Kim, M. B. Kastan, Mol. Cell. Biol. 21, 3445 (2001).

17. Q. Liu et al., Genes Dev. 14, 1448 (2000).

18. H. Takai et al., Genes Dev. 14, 1439 (2000).

19. R. I. Yarden, S. Pardo-Reoyo, M. Sgagias, K. H. Cowan, L. C. Brody, Nat. Genet. 30, 285 (2002).

20. P. B. Deming et al., Proc. Natl. Acad. Sci. U.S.A. 98, 12044 (2001)
21. X. Yu, S. Fu, M. Lai, R. Baer, ]. Chen, Genes Dev. 20, 1721 (2006).

22. X. Wang, P. R. Andreassen, A. D. D'Andrea, Mol. Cell. Biol. 24, 5850 (2004).

23. R. Montes de Oca et al., Blood 105, 1003 (2005).

24. We thank ]. Wood for proofreading the manuscript; ]. Hohfeld and B. Horazdovsky for providing constructs encoding HSJ1A and Ubi-GST, respectively; and A. D'Andrea for providing FANCD2-deficient and FANCD2-reconstituted cells. This work was supported by grants from NIH (grant number R01CA089239 to J.C.), the Ovarian Cancer Research Fund (X.Y.), the University of Michigan Cancer Center Developmental Fund (X.Y.), the U.S. Department of Defense (DOD) Era of Hope Scholars Award (J.C.), and the DOD Breast Cancer Research Program Idea Award (X.Y.).

\section{Supporting Online Material}

www.sciencemag.org/cgi/content/full/316/5828/1202/DC1

Materials and Methods

Figs. $\mathrm{S} 1$ to $\mathrm{S} 9$

References

5 January 2007; accepted 10 April 2007

$10.1126 /$ science. 1139621

\title{
How Synaptotagmin Promotes Membrane Fusion
}

\author{
Sascha Martens, ${ }^{1}$ Michael M. Kozlov, ${ }^{2}$ Harvey T. McMahon ${ }^{1 *}$
}

Synaptic vesicles loaded with neurotransmitters are exocytosed in a soluble $\mathrm{N}$-ethylmaleimidesensitive factor attachment protein receptor (SNARE)-dependent manner after presynaptic depolarization induces calcium ion $\left(\mathrm{Ca}^{2+}\right)$ influx. The $\mathrm{Ca}^{2+}$ sensor required for fast fusion is synaptotagmin-1. The activation energy of bilayer-bilayer fusion is very high ( $\left.\approx 40 k_{\mathrm{B}} T\right)$. We found that, in response to $\mathrm{Ca}^{2+}$ binding, synaptotagmin-1 could promote SNARE-mediated fusion by lowering this activation barrier by inducing high positive curvature in target membranes on C2domain membrane insertion. Thus, synaptotagmin-1 triggers the fusion of docked vesicles by local $\mathrm{Ca}^{2+}$-dependent buckling of the plasma membrane together with the zippering of SNAREs. This mechanism may be widely used in membrane fusion.

A $\mathrm{t}$ the synapse, neurotransmitter release is mediated by the $\mathrm{Ca}^{2+}$-induced fusion of transmitter-loaded synaptic vesicles with the presynaptic plasma membrane. The plasma membrane-localized target (t)-SNAREs ([soluble $N$-ethylmaleimide-sensitive factor attachment protein 25 (SNAP-25) and syntaxin-1)] and the vesicle (v)-localized v-SNARE (synaptobrevin) and synaptotagmin-1 (syt1) are involved in the $\mathrm{Ca}^{2+}$-triggered fusion of synaptic vesicles with the plasma membrane (1). The three SNAREs are believed to bring the two membranes destined for fusion into close apposition. Syt1 has been shown to be the $\mathrm{Ca}^{2+}$ sensor responsible for $\mathrm{Ca}^{2+}$-triggered fusion (2), but the molecular mechanism by which syt1 accomplishes this is not fully understood. Syt1 is a vesicle-localized transmembrane protein with

${ }^{1}$ Medical Research Council-Laboratory of Molecular Biology, Hills Road, CB2 0QH Cambridge, UK. ${ }^{2}$ Department of Physiology and Pharmacology, Sackler Faculty of Medicine, Tel Aviv University, 69978 Tel Aviv, Israel.

*To whom correspondence should be addressed. E-mail: hmm@mrc-lmb.cam.ac.uk two cytoplasmic $\mathrm{C} 2$ domains, $\mathrm{C} 2 \mathrm{~A}$ and $\mathrm{C} 2 \mathrm{~B}$ (Fig. 1A). The $\mathrm{C} 2 \mathrm{~A}$ and the $\mathrm{C} 2 \mathrm{~B}$ domains each bind $\mathrm{Ca}^{2+}$, which enables them to interact with membranes $(3,4)$. This activity is implicated in the triggering of membrane fusion $(5,6)$. In addition, $\mathrm{Ca}^{2+}$-dependent and -independent interactions between syt1 with SNAREs have been shown (7).

The fusion of two membranes is now widely believed to occur through a hemifusion intermediate (8). For hemifusion to occur, high energy barriers must be overcome, which are thought to be related to the curvature deformations generated within the membranes during stalk formation and subsequent stages of membrane merging $(8,9)$. Syt1 has been shown to trigger $\mathrm{Ca}^{2+}$-induced fusion and bind to membranes in a $\mathrm{Ca}^{2+}$-dependent manner, and thus we investigated whether it could promote membrane fusion and, consequently, exocytosis, by affecting local membrane curvature.

$\mathrm{Ca}^{2+}$ binding by syt 1 is mediated by a series of conserved aspartate residues that line pockets on one end of each of the $\mathrm{C} 2 \mathrm{~A}$ and C2B domains $(3,10)$ (Fig. 1A). We used a syt1 construct lacking the transmembrane domain but having the double $\mathrm{C} 2$ domain module (C2AB) (11). $\mathrm{Ca}^{2+}$ binding allows the $\mathrm{C} 2 \mathrm{~A}$ and $\mathrm{C} 2 \mathrm{~B}$ domains to interact with negatively charged phospholipids such as phosphatidylserine (PtdSer) and phosphatidylinositol-4,5bisphosphate $\left[\operatorname{PtdIns}(4,5) \mathrm{P}_{2}\right](12,13)$ (fig. S1). This interaction results in the insertion of four loops (two from each of the $\mathrm{C} 2$ domains) into the lipid bilayer $(14,15)$. M173, F234, V304, and I367 (16) located on the tips of the membrane-binding loops (Fig. 1A) penetrate to a third of the lipid monolayer depth (15). This kind of hydrophobic-loop insertion should generate a tendency for the monolayer to bend to relieve the tension created by the insertion. If syt1 contributes to spontaneous membrane curvature $(8)$, the closer the membrane curvature is to that preferentially produced by syt1, the stronger the syt1 affinity for membrane binding should be. Conversely, addition of syt 1 to initially flat membranes should induce a positive curvature.

We incubated liposomes of different sizes, and, consequently, of different curvatures, with syt1 $\mathrm{C} 2 \mathrm{AB}$ domains in the presence and absence of $1 \mathrm{mM} \mathrm{Ca}^{2+}$. The binding of syt1 to membranes was monitored by a cosedimentation assay (Fig. 1B). Syt1 showed a clear preference for binding smaller liposomes (Fig. 1, Bii and C). This effect was observed only in the presence of $\mathrm{Ca}^{2+}$, whereas the $\mathrm{Ca}^{2+}$-independent interaction of syt1 with liposomes was size independent (Fig. 1Bi). This positive-curvature preference was largely lost when we increased the strength of interaction of syt1 with the membrane by elevating the PtdSer content in the liposomes from 15 to $25 \%$ (Fig. 1D). Likewise, the binding to Folch liposomes, which are rich in PtdSer, was largely curvature independent. The syt1 $\mathrm{C} 2 \mathrm{AB}$ domain 
thus lost its ability to sense membrane curvature when the strength of interaction with the membrane was increased. To determine if the insertion of the hydrophobic loops accounted for syt1's preferential binding to small liposomes, we mutated M173, F234, V304, and I367 to alanines (4A mutant). The $4 \mathrm{~A}$ mutant bound to $0.8-\mu \mathrm{m}$ liposomes with an affinity similar to that of wildtype syt1 but showed no increased binding to small liposomes (Fig. 1, Biii and C). A mutant with all four residues mutated to tryptophans (4W mutant) showed an increased curvature preference (Fig. 1, Biv and C), but like the wild-type $\mathrm{C} 2 \mathrm{AB}$ domain, lost its curvature preference when the PtdSer content in the liposomes was increased to $25 \%$. Another mutant, K326E, with a point mutation in the polybasic region of the $\mathrm{C} 2 \mathrm{~B}$ domain that is remote from the $\mathrm{Ca}^{2+}$-dependent membrane interaction site (Fig. 1A), was defective in $\mathrm{Ca}^{2+}$. independent binding to liposomes but showed unaltered $\mathrm{Ca}^{2+}$-mediated membrane interactions (fig. S1). Furthermore, as expected, K326E bound more effectively to small liposomes (Fig. $1, \mathrm{Bv}$ and $\mathrm{C}$ ).

To determine if syt1 could induce positive membrane curvature, we incubated Folch liposomes with syt1 in the presence and absence of $\mathrm{Ca}^{2+}$. We observed extensive tubulation of Folch liposomes by syt1 only in the presence of $\mathrm{Ca}^{2+}$ (Fig. 2, A and B). The average diameter of tubules was $17.5 \pm 3 \mathrm{~nm}$ from outer bilayer to outer bilayer, showing that the interaction of syt1 with membranes results in the induction of high positive curvature. For comparison, the N-BAR module (Bin/amphiphysin/Rvs domain with an N-terminal amphipathic helix) of amphiphysin makes lipid tubules of $46 \mathrm{~nm}$ (17). Using the syt1 $\mathrm{C} 2 \mathrm{~A}$ and $\mathrm{C} 2 \mathrm{~B}$ crystal structures $(3,10)$ and the depth of insertions determined by electron paramagnetic resonance spectroscopy (15), we estimated that $\sim 30 \%$ of the tubular surface needs to be covered to stabilize this curvature.

The tubulation of liposomes required the $\mathrm{C} 2 \mathrm{~A}$ and $\mathrm{C} 2 \mathrm{~B}$ domains to be linked to each other; the separated $\mathrm{C} 2 \mathrm{~A}$ and $\mathrm{C} 2 \mathrm{~B}$ domains did not tubulate Folch liposomes in the presence of $\mathrm{Ca}^{2+}$ (Fig. 2C). The 4A mutant failed to induce tubulation of Folch liposomes; in contrast, the $4 \mathrm{~W}$ mutant caused tubulation and fragmentation of the liposomes, indicating further destabilization of the membrane (Fig. 2, D and E, and fig. S2). This destabilization is likely to have resulted from the greater volume occupied by the bulkier residues within the monolayer. The K326E mutant showed tubulation to an extent similar to that shown by the wildtype $\mathrm{C} 2 \mathrm{AB}$ fragment (Fig. 2F). A C2AB fragment with mutations in the $\mathrm{Ca}^{2+}$-binding site of the C2A domain (D230N, D232N) tubulated Folch liposomes (Fig. 2G), whereas a $\mathrm{C} 2 \mathrm{AB}$ fragment with mutations in the $\mathrm{Ca}^{2+}$-binding site of the C2B domain (D363N, D365N) did not induce membrane curvature (Fig. $2 \mathrm{H}$ ). These results correlate with the ability of the former and inability of the latter mutant to promote synaptic vesicle exocytosis in vivo $(18,19)$. We next investigated whether the tubulation of liposomes required the specific presence of the $\mathrm{C} 2 \mathrm{~A}$ and the $\mathrm{C} 2 \mathrm{~B}$ domains by fusing two $\mathrm{C} 2 \mathrm{~A}$ domains $(\mathrm{C} 2 \mathrm{AA})$ and two $\mathrm{C} 2 \mathrm{~B}$ domains $(\mathrm{C} 2 \mathrm{BB})$ and incubating them with liposomes in the presence of $\mathrm{Ca}^{2+}$. Both fragments tubulated liposomes (Fig. 2, I and J), suggesting that the requirement for the induction of positive membrane curvature is the presence of two tethered $\mathrm{C} 2$ domains and their penetration of the lipid monolayer.

Next, we examined whether the $\mathrm{Ca}^{2+}$. dependent induction of membrane curvature by syt1 is required for the promotion of SNAREmediated membrane fusion in an in vitro assay $(11,20,21)$. SNAREs alone were inefficient in promoting fusion of liposomes (Fig. 3A). Fulllength syt1 had no effect in this assay but, as expected (21), we observed accelerated fusion by the addition of syt1 $\mathrm{C} 2 \mathrm{AB}$ domain only in the presence of $\mathrm{Ca}^{2+}$ (Fig. 3A). This effect depended absolutely on the presence of SNAP-25 and syntaxin-1 in the target liposomes (Fig. 3A). The $\mathrm{C} 2 \mathrm{~A}$ and $\mathrm{C} 2 \mathrm{~B}$ domains had to be linked in order to promote membrane fusion (fig. S3) (21). The 4A mutant was unable to promote membrane fusion, whereas the $4 \mathrm{~W}$ mutant showed increased promotion of membrane fusion compared with the wild-type $\mathrm{C} 2 \mathrm{AB}$ fragment (Fig. 3B). Indeed, the expression in hippocampal neurons of a mutant syt1 carrying tryptophans in the membranebinding loops results in an increased probability of synaptic vesicle release ( 6 ). The inability of the 4A mutant to promote membrane fusion was not due to its lower affinity for membranes, because increasing the concentration of the $4 \mathrm{~A}$ mutant in the membrane fusion assay did not lead to increased fusion but rather led to a slight inhibition, perhaps due to masking of phospholipids (fig. S3). The K326E mutant, which could induce membrane curvature (Fig. 2), promoted membrane fusion to an extent similar to that shown by the wild-type protein, suggesting that the polybasic stretch was not required for the promotion of fusion in vitro (Fig. 3B). These results correlate well with the ability of wild-type syt1 and the syt1 mutants to induce tubulation of liposomes (Fig. 2).

Next, we tested the syt1 C2AA and C2BB domains for their ability to promote SNAREdependent membrane fusion (Fig. 3C). Both proteins were indeed able to tubulate liposomes (Fig. 2). In our fusion assay, however, the C2AA domain was unable to promote fusion, whereas the $\mathrm{C} 2 \mathrm{BB}$ domain was even more active than the syt1 $\mathrm{C} 2 \mathrm{AB}$ domain, indicating that the induction
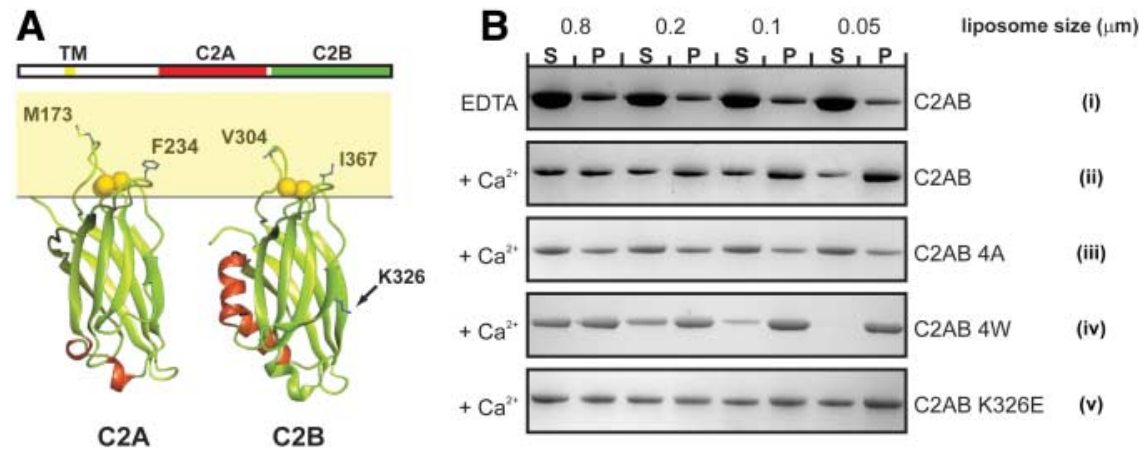

C

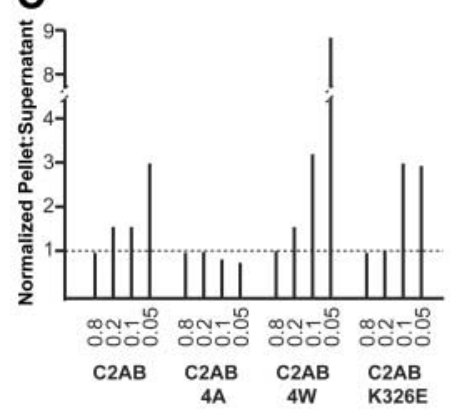

D

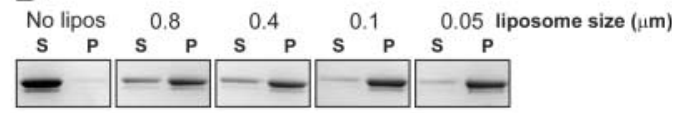

Fig. 1. Curvature preference of liposome binding by wildtype and mutant syt1. (A) Domain structure of syt1 (TM: transmembrane domain) and structures of the cytoplasmic $\mathrm{C} 2 \mathrm{~A}$ and $\mathrm{C} 2 \mathrm{~B}$ domains [Protein Data Bank accession numbers: 1BYN (27), 1UOW (28)]. Residues mutated in this study are highlighted. $\mathrm{Ca}^{2+}$ ions are shown as yellow spheres. The membrane into which the $\mathrm{C} 2$ domains insert is indicated by the yellow box. The depth of membrane insertion is shown according to (15). (B) Lipid cosedimentation assay. The indicated proteins were incubated with liposomes of different sizes $(0.8$ to $0.05 \mu \mathrm{m})$ in the absence $(1 \mathrm{mM}$ EDTA) or presence of $1 \mathrm{mM} \mathrm{Ca}{ }^{2+}$. $P$, pellet formed by centrifuging; $S$, supernatant. Representative gels from one of three independent experiments are shown. (C) Quantification of lipid cosedimentation experiments presented in (B). The P/S ratio for the $0.8-\mu \mathrm{m}$ liposomes was set to 1 . The numbers indicate the size of the liposomes (in micrometers). (D) The curvature preference of syt1 for smaller liposomes is largely lost when the PtdSer content is increased to $25 \%$, as determined by liposome cosedimentation. The numbers indicate the size of the liposomes used for cosedimentation. 
of membrane curvature alone is not sufficient to promote fusion. We attribute the lack of fusionpromoting activity by the $\mathrm{C} 2 \mathrm{AA}$ domain to its inability to correctly interact with the SNARE complex, whereas the $\mathrm{C} 2 \mathrm{BB}$ domain might be better positioned in respect to the SNARE complex. The $\mathrm{C} 2 \mathrm{~B}$ domain interacts more strongly with the SNARE complex (22).
We further tested the syt $4 \mathrm{C} 2 \mathrm{AB}$ domain in our fusion assay. Syt4 lacks $\mathrm{Ca}^{2+}$-dependent phospholipid-binding activity and did not tubulate Folch liposomes (fig. S1), but it displays SNARE binding to an extent similar to that shown by the syt1 C2AB domain (23). The syt4 $\mathrm{C} 2 \mathrm{AB}$ domain failed to promote fusion (Fig. 3C), indicating that membrane binding and defor-
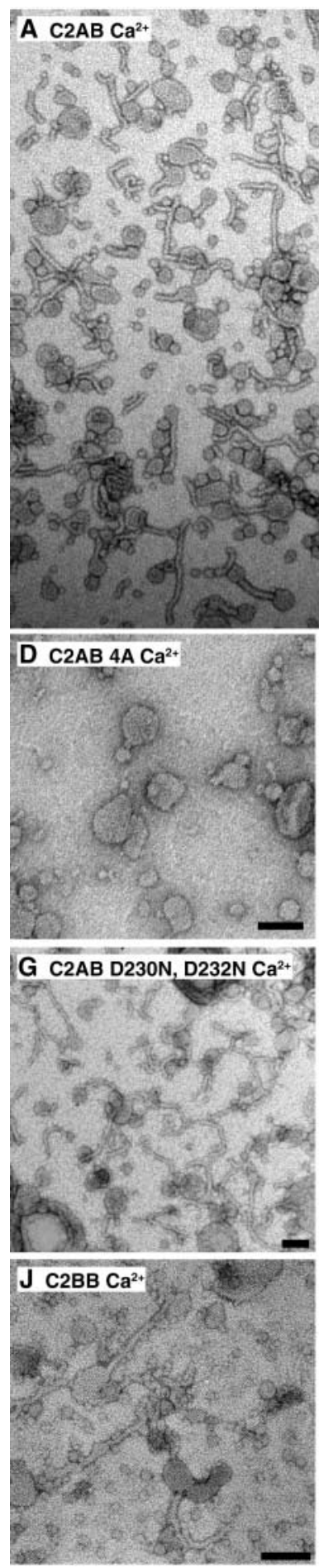
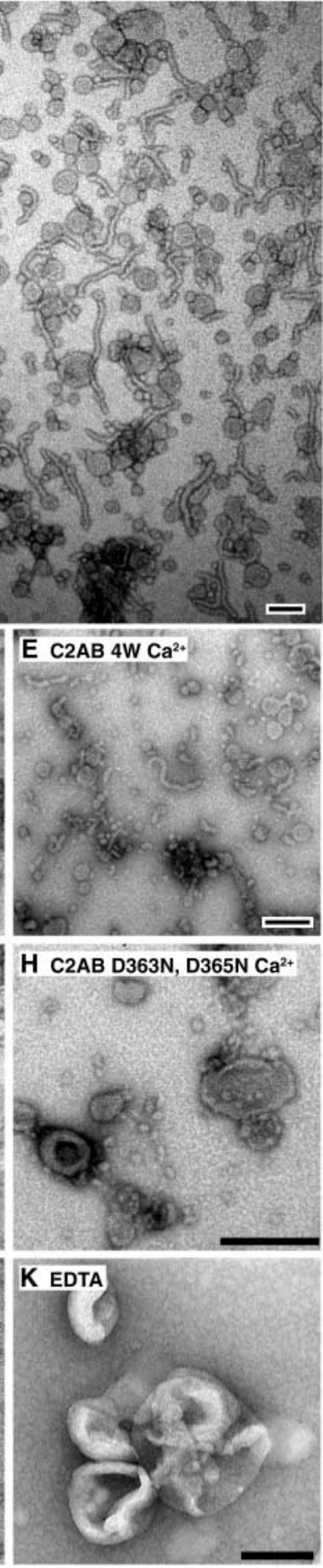
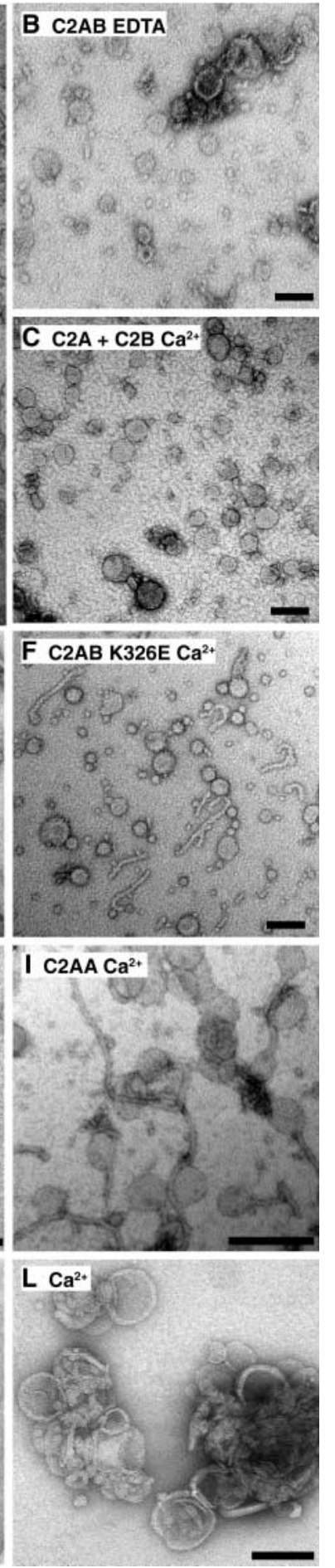

Fig. 2. $\mathrm{Ca}^{2+}$-dependent induction of positive membrane curvature seen as tubulation by wild-type and mutant syt1. (A to $\mathbf{L}$ ) Electron micrographs of Folch liposomes incubated with the indicated proteins at a concentration of $10 \mu \mathrm{M}$ (11). Scale bar: $100 \mathrm{~nm}$.

mation by synaptotagmins are essential for the promotion of membrane fusion.

We further tested three synaptotagmin-related proteins - syt3, syt9, and synaptotagmin-like protein 2 (slp2)-for the induction of membrane curvature (Fig. 3). Syt3 and syt9 showed substantial $\mathrm{Ca}^{2+}$-independent binding to liposomes, which increased upon the addition of $\mathrm{Ca}^{2+}$, whereas the binding of $\operatorname{slp} 2$ to Folch liposomes was not affected by $\mathrm{Ca}^{2+}$ (Fig. 3D). Syt3 and syt9 both tubulated Folch liposomes in a $\mathrm{Ca}^{2+}$-dependent manner, whereas slp2 tubulation did not require $\mathrm{Ca}^{2+}$ (Fig. 3E). The induction of positive curvature in the target membrane thus appears to be a property shared by many double $\mathrm{C} 2$ domaincontaining proteins.

We propose the following model for the action of syt1 during $\mathrm{Ca}^{2+}$-dependent synaptic vesicle release (fig. S4). Because of its $\mathrm{Ca}^{2+}$-independent interaction with the tSNAREs and/or $\operatorname{PtdIns}(4,5) \mathrm{P}_{2}$ in the plasma membrane $(13,24)$, syt1 in the synaptic vesicle is closely associated with the transSNARE complexes, which have been suggested to be ordered ringwise around the future fusion site (20). Upon $\mathrm{Ca}^{2+}$ influx and subsequent $\mathrm{Ca}^{2+}$ binding by syt1, the $\mathrm{C} 2 \mathrm{~A}$ and $\mathrm{C} 2 \mathrm{~B}$ domains penetrate the plasma membrane, resulting in the local induction of positive membrane curvature under the SNARE complex ring. This causes buckling toward the synaptic vesicle of the plasma membrane within the SNARE ring, reducing the distance between the two membranes. Furthermore, the buckled membrane is under curvature stress, which reduces the energy barrier the membrane has to overcome at the intermediate stage of fusion and, hence, accelerates the fusion reaction. An estimate of the energy released on going from buckle to stalk formation is $20 k_{\mathrm{B}} T$. This reduces the overall energy of stalk formation from $\sim 40 k_{\mathrm{B}} T$ (9) to about $20 k_{\mathrm{B}} T(11)$. The remaining energy can be overcome by the membrane spontaneously $(9,25)$. According to our model, syt1 has to bind the SNARE complex in order to target the membrane buckle under the vesicle. Indeed, the failure of syt1 to promote yeast SNARE-mediated membrane fusion correlates with its inability to bind the yeast SNAREs (26).

We have shown that, for syt1, the multiple $\mathrm{C} 2$ domain (MC2D) module promotes membrane fusion by the $\mathrm{Ca}^{2+}$-dependent induction of membrane curvature, explaining how syt 1 couples $\mathrm{Ca}^{2+}$ entry into a synapse to vesicle fusion. MC2D-containing proteins are found throughout the eukaryotic kingdom and constitute a large protein superfamily that includes molecules such as synaptotagmin-like proteins, ferlins, rabphilin, Rim, and DOC2. The promotion of membrane fusion by local induction of membrane curvature stress by MC2Dcontaining proteins may thus be a widespread phenomenon.

References and Notes

1. T. C. Sudhof, Annu. Rev. Neurosci. 27, 509 (2004).

2. M. Geppert et al., Cell 79, 717 (1994). 
A
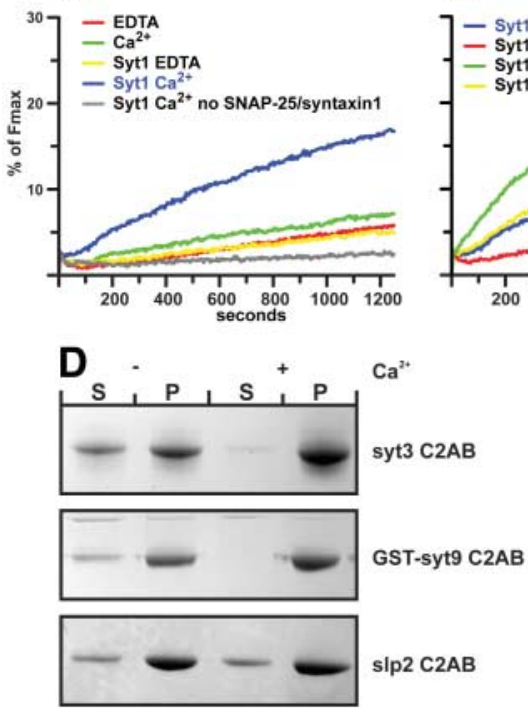

Fig. 3. Reconstitution of membrane fusion in vitro and liposome-binding and tubulation by synaptotagminrelated proteins. (A) Fusion of tSNARE and vSNARE liposomes was monitored by dequenching of NBD [N-(7nitro-2-1, 3-benzoxadiazol-4-yl] upon lipid mixing. Syt1 was added at a concentration of $7.5 \mu \mathrm{M}$ and $\mathrm{Ca}^{2+}$ was added to a final concentration of $500 \mu \mathrm{M}$. The maximal fluorescence $\left(F_{\max }\right)$ was determined by the addition of $1 \%$ Triton X-100. (B) Same fusion assay as in (A), showing the indicated syt1 mutants used at a concentration of $7.5 \mu \mathrm{M}$. (C) Fusion assay as in $(A)$ with the $C 2 A B$, $C 2 A A, C 2 B B$, and syt4 C2AB domains at a concentration of $7.5 \mu \mathrm{M}$. (D) Co-sedimentation assay using Folch liposomes and the indicated proteins. (E) Electron micrographs of Folch liposomes incubated with the indicated proteins. $\mathrm{Ca}^{2+}$ was added to a final concentration of $1 \mathrm{mM}$ in (D) and (E). Scale bar: $100 \mathrm{~nm}$.

3. I. Fernandez et al., Neuron 32, 1057 (2001).

4. B. A. Davletov, T. C. Sudhof, J. Biol. Chem. 268, 26386 (1993).

5. R. Fernandez-Chacon et al., Nature 410, 41 (2001)

6. J. S. Rhee et al., Proc. Natl. Acad. Sci. U.S.A. 102, 18664 (2005).
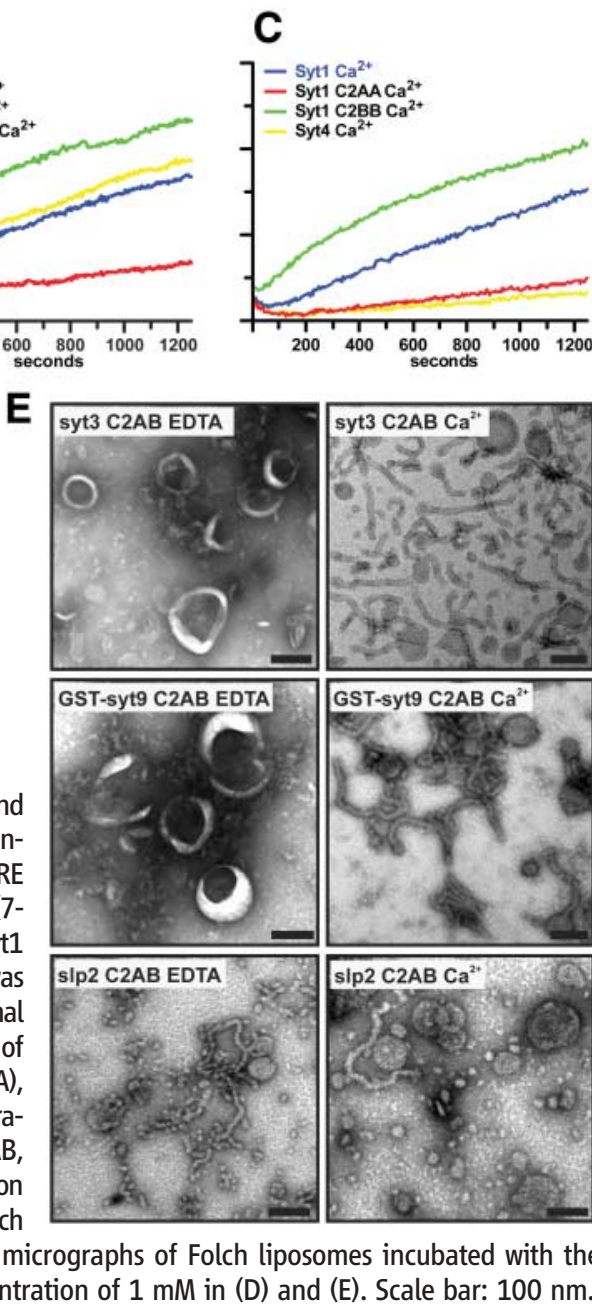

7. J. Tang et al., Cell 126, 1175 (2006)

8. L. V. Chernomordik, M. M. Kozlov, Annu. Rev. Biochem. $72,175(2003)$

9. Y. Kozlovsky, M. M. Kozlov, Biophys. J. 82, 882 (2002).

10. R. B. Sutton, B. A. Davletov, A. M. Berghuis, T. C. Sudhof, S. R. Sprang, Cell 80, 929 (1995).
11. Materials and methods and calculations are available as supporting material on Science Online.

12. M. S. Perin, V. A. Fried, G. A. Mignery, R. Jahn, T. C. Sudhof Nature 345, 260 (1990).

13. J. Bai, W. C. Tucker, E. R. Chapman, Nat. Struct. Mol. Biol. 11, 36 (2004)

14. E. Hui, J. Bai, E. R. Chapman, Biophys. J. 91, 1767 (2006)

15. D. Z. Herrick, S. Sterbling, K. A. Rasch, A. Hinderliter, D. S. Cafiso, Biochemistry 45, 9668 (2006).

16. Single-letter abbreviations for the amino acid residues used are as follows: A, Ala; D, Asp; F, Phe; K, Lys; L, Leu; M, Met; V, Val; and W, Trp.

17. B. J. Peter et al., Science 303, 495 (2004).

18. I. M. Robinson, R. Ranjan, T. L. Schwarz, Nature 418 336 (2002)

19. J. M. Mackler, J. A. Drummond, C. A. Loewen, I. M. Robinson, N. E. Reist, Nature 418, 340 (2002).

20. T. Weber et al., Cell 92, 759 (1998).

21. W. C. Tucker, T. Weber, E. R. Chapman, Science 304, 435 (2004)

22. H. Dai, N. Shen, D. Arac, J. Rizo, J. Mol. Biol. 367, 848 (2007).

23. C. Rickman, M. Craxton, S. Osborne, B. Davletov, Biochem. J. 378, 681 (2004).

24. C. Rickman et al., Mol. Biol. Cell 17, 283 (2006).

25. P. I. Kuzmin, ]. Zimmerberg, Y. A. Chizmadzhev, F. S. Cohen, Proc. Natl. Acad. Sci. U.S.A. 98, 7235 (2001).

26. A. Bhalla, M. C. Chicka, W. C. Tucker, E. R. Chapman, Nat. Struct. Mol. Biol. 13, 323 (2006)

27. X. Shao, I. Fernandez, T. C. Sudhof, J. Rizo, Biochemistry 37, 16106 (1998).

28. Y. Cheng et al., Protein Sci. 13, 2665 (2004).

29. We thank B. Davletov for the provision of synaptotagmin 3, 4, and 9 plasmids and members of the lab for extensive discussions. This work was supported by the Medical Research Council (UK). We also gratefully acknowledge a long-term fellowship from the European Molecular Biology Organization (ALTF 21-2006) to S.M. and the Israel Science Foundation, United States-Israel Binational Science Foundation, and the Marie Curie Network "Flippases" funding for M.M.K.

Supporting Online Material

www.sciencemag.org/cgi/content/full/316/5828/1205/DC1

Materials and Methods

SOM Text

Figs. S1 to S6

References

12 January 2007; accepted 17 April 2007

Published online 3 May 2007;

10.1126/science.1142614

Include this information when citing this paper.

\section{Myosin V Walks by Lever Action and Brownian Motion}

Katsuyuki Shiroguchi and Kazuhiko Kinosita Jr.*

Myosin V is a molecular motor that moves cargo along actin filaments. Its two heads, each attached to a long and relatively stiff neck, move alternately forward in a "hand-over-hand" fashion. To observe under a microscope how the necks move, we attached a micrometer-sized rod to one of the necks. The leading neck swings unidirectionally forward, whereas the trailing neck, once lifted, undergoes extensive Brownian rotation in all directions before landing on a site ahead of the leading head. The neck-neck joint is essentially free, and the neck motion supports a mechanism where the active swing of the leading neck biases the random motion of the lifted head to let it eventually land on a forward site.

$\mathrm{L}$ inear molecular motors such as myosin, kinesin, or dynein are often Y-shaped, with two identical arms of $Y$ each ending in a globular motor domain that binds to a track in an adenosine triphosphate (ATP)-dependent manner. Traditionally the motor domain has been called a "head" and the rest of the arm a "neck" (Fig. 1A). How the heads and necks cooperate to propel the motor is best understood in those motors that take many discrete steps without falling off a filamentous track (1-7): The two heads move forward alternately in a "hand-overhand" fashion, as in human walking (8-11). However, the mechanism for bringing the lagging head onto a forward landing site is not yet firmly established. Here we focus on myosin V $(12,13)$ that walks on an actin filament with $\sim 35$-nm steps $(14,15)$. The necks of this motor are stiff relative to those of other motors such as kinesin, and they are called "lever arms" because they would serve as a lever. In electron micrographs (16), myosin V's long necks form a V-shape when both heads are attached to actin. Every step would thus result in leaning of a neck alternately forward and backward, as indeed was shown when a fluorophore

Department of Physics, Faculty of Science and Engineering, Waseda University, Okubo 3-4-1, Shinjuku-ku, Tokyo 1698555, Japan.

*To whom correspondence should be addressed. E-mail: kazuhiko@waseda.jp 


\title{
Science \\ \IAAAS
}

www.sciencemag.org/cgi/content/full/1142614/DC1

\section{Supporting Online Material for}

\section{How Synaptotagmin Promotes Membrane Fusion}

\author{
Sascha Martens, Michael M. Kozlov, Harvey T. McMahon*
}

*To whom correspondence should be addressed. E-mail: hmm@mrc-lmb.cam.ac.uk

Published 3 May 2007 on Science Express

DOI: $10.1126 /$ science.1142614

\section{This PDF file includes:}

Materials and Methods

SOM Text

Figs. S1 to S6

References

Correction: In the "Protein expression" section of the Materials and Methods, it was incorrectly stated that the C2B domain construct of synaptotagmin ended in residue 408. It should have read: "The C2B domain comprised amino acids 273-421." 


\title{
Supporting Online Material for How Synaptotagmin Promotes Membrane Fusion
}

\author{
Sascha Martens ${ }^{1}$, Michael M. Kozlov ${ }^{2}$ and Harvey T. McMahon ${ }^{1 *}$ \\ ${ }^{1}$ MRC-Laboratory of Molecular Biology, Hills Road, CB2 0QH Cambridge, UK \\ ${ }^{2}$ Department of Physiology and Pharmacology, Sackler Faculty of Medicine, Tel \\ Aviv University, 69978 Tel Aviv, Israel
}

*To whom correspondence should be addressed. E-mail: hmm@mrc-lmb.cam.ac.uk

This PDF file includes:

Materials and Methods

Calculations

Figs. S1 to S6

References 


\section{$\underline{\text { Material and Methods }}$}

\section{Protein expression}

All synaptotagmin fragments were expressed as GST fusion proteins from pGEX4T2 or pGEX4T1. The $\mathrm{C} 2 \mathrm{AB}$ domain constructs comprised amino acids $96-421$ of rat synaptotagmin-1. The C2A domain comprised amino acids $142-262$ of rat synaptotagmin-1 and the $\mathrm{C} 2 \mathrm{~B}$ domain comprised amino acids 273-421. Mutations into the $\mathrm{C} 2 \mathrm{AB}$ domain construct were introduced according to the Stratagene Quick Change protocol (see Fig. S5 for a list of mutants). The syt3, syt4 and syt9 C2AB domain fragments are described in $(S 1)$. The slp2 $\mathrm{C} 2 \mathrm{AB}$ domain fragment comprised amino acids $597-910$ of human slp2a.

The C2AA domain construct was generated as follows: A fragment containing the cytoplasmic linker (starting at amino acid 96) connecting the transmembrane with the $\mathrm{C} 2 \mathrm{~A}$ domain, the $\mathrm{C} 2 \mathrm{~A}$ domain and the linker between the $\mathrm{C} 2 \mathrm{~A}$ and $\mathrm{C} 2 \mathrm{~B}$ domain was amplified by PCR and cloned into pGEX4T1 via BamHI-SalI. Subsequently a PCRfragment containing only the $\mathrm{C} 2 \mathrm{~A}$ domain was cloned into the construct containing the first fragment via SalI-NotI.

The $\mathrm{C} 2 \mathrm{BB}$ domain construct was generated as follows: First a fragment comprising the cytoplasmic linker (starting at amino acid 96) connecting the transmembrane with the C2A domain was amplified by PCR and cloned into pGEX-4T1 via BamHIEcoRI. Then a fragment comprising the $\mathrm{C} 2 \mathrm{~B}$ domain was cloned into the vector containing the cytoplasmic linker via EcoRI-SalI. Finally a fragment containing the linker between the $\mathrm{C} 2 \mathrm{~A}$ and $\mathrm{C} 2 \mathrm{~B}$ domain and the $\mathrm{C} 2 \mathrm{~B}$ domain was cloned into the vector containing the first two fragments via SalI-NotI.

For expression of the syt $1 \mathrm{C} 2 \mathrm{AB}, \mathrm{C} 2 \mathrm{~A}, \mathrm{C} 2 \mathrm{~B}, \mathrm{C} 2 \mathrm{AA}$ and $\mathrm{C} 2 \mathrm{BB}$ domain fragments and the syt3 $\mathrm{C} 2 \mathrm{AB}$, syt4 $\mathrm{C} 2 \mathrm{AB}$ and slp2 $\mathrm{C} 2 \mathrm{AB}$ domain fragments BL21(DE3) pLysS cells (Stratagene) were used. Cells were grown at $37^{\circ} \mathrm{C}$ until $\mathrm{OD}_{600}$ of 0.3 , induced with $40 \mu \mathrm{M}$ IPTG and grown for $14-16 \mathrm{~h}$ at $18^{\circ} \mathrm{C}$. Cells were harvested and resuspended in 50mM HEPES pH7.5, 300mM NaCl, 4mM DTT, 2mM $\mathrm{MgCl}_{2}$, DNaseI, RNaseA and lysed by freeze thawing. The lysate was centrifuged for $45 \mathrm{~min}$ at $125,000 \mathrm{~g}, 4^{\circ} \mathrm{C}$ and the supernatant was incubated with $1 \mathrm{ml}$ of glutathione beads (GE healthcare) per 11 of culture for $1-2 \mathrm{~h}$. Beads were washed 7 times with $50 \mathrm{mM}$ HEPES pH 7.5, 300mM NaCl, 4mM DTT followed by two $15 \mathrm{~min}$ washes with $50 \mathrm{mM}$ HEPES pH7.5, 500mM NaCl, $2 \mathrm{mM} \mathrm{MgCl}_{2}$, DNaseI, RNaseA. The protein was cleaved off the beads with thrombin by over night incubation at $4^{\circ} \mathrm{C}$. The supernatant was concentrated and the protein was further purified by gelfiltration in $50 \mathrm{mM}$ HEPES pH7.5, 150mM NaCl, 4mM DTT using a HiLoad 16/60 Superdex 75 column (Pharamcia Biotech). For the $4 \mathrm{~W}$ mutant the gelfiltration was conducted with $300 \mathrm{mM}$ $\mathrm{NaCl}$ instead of $150 \mathrm{mM} \mathrm{NaCl}$. The syt $9 \mathrm{C} 2 \mathrm{AB}$ domain fragment was purified as described above except that the protein was eluted from the glutathione beads with $100 \mathrm{mM}$ glutathione and subsequently gelfiltered. GST-syt9 C2AB was used for the experiments. The proteins were shock frozen and stored at $-80^{\circ} \mathrm{C}$. Possible protein and RNA contamination was checked by SDS gel electrophoresis and UV spectroscopy, respectively.

Rat full length SNAP-25 and full length synatxin1 were expressed as GST fusion proteins in BL21(DE3) pLysS cells (Stratagene). Cells were grown at $37^{\circ} \mathrm{C}$ until OD600 of $0.9-1$, induced with $500 \mu \mathrm{M}$ IPTG and grown for $4 \mathrm{~h}$ at $37^{\circ} \mathrm{C}$. Cells were harvested and resuspended in $50 \mathrm{mM}$ Tris $\mathrm{pH} 8,300 \mathrm{mM} \mathrm{KCl}, 10 \%$ glycerol, $5 \%$ Triton X-100, 5mM DTT, $2 \mathrm{mM} \mathrm{MgCl} 2$, DNaseI, EDTA-free Complete protease inhibitors (Roche) and lysed by freeze thawing. The lysate was centrifuged for $45 \mathrm{~min}$ at 
$125,000 \mathrm{~g}, 4^{\circ} \mathrm{C}$ and the supernatant was incubated with $1 \mathrm{ml}$ of glutathione beads (GE Healthcare) per 11 of culture for $1-2 \mathrm{~h}$. Beads were washed $6 \mathrm{x}$ with $50 \mathrm{mM}$ Tris $\mathrm{pH} 8$, $300 \mathrm{mM} \mathrm{KCl}, 10 \%$ glycerol, $1 \%$ Triton X-100, 5mM DTT, EDTA-free Complete protease inhibitors (Roche) and subsequently washed with over 20 bead volumes of $50 \mathrm{mM}$ Tris $\mathrm{pH} 8,100 \mathrm{mM} \mathrm{KCl}, 0.8 \%$ w/v n-octyl $\beta$-D-glucopyranoside (OGP), $5 \mathrm{mM}$ DTT. SNAP-25 and syntaxin-1a were cleaved off the beads with thrombin over night at $4{ }^{\circ} \mathrm{C}$. Thrombin was then inactivated by the addition of $0.1 \mathrm{mM}$ PMSF followed by $1 \mathrm{~h}$ incubation at room temperature. The supernatant was shock frozen and stored at $80^{\circ} \mathrm{C}$.

Rat full length synaptobrevin was expressed as GST fusion protein from pGEX4T1 in BL21(DE3) pLysS cells. Cells were grown at $37^{\circ} \mathrm{C}$ until $\mathrm{OD}_{600}$ of 0.3 , induced with $40 \mu \mathrm{M}$ IPTG and grown for $14-16 \mathrm{~h}$ at $18^{\circ} \mathrm{C}$. Cells were harvested and resuspended in $25 \mathrm{mM}$ HEPES pH7.5, 400mM KCl, 5\% Triton X-100, $10 \%$ glycerol, $2 \mathrm{mM} \mathrm{MgCl}_{2}$, $4 \mathrm{mM}$ DTT, EDTA-free Complete protease inhibitors (Roche), 0.2mM PMSF, DNaseI. Cells were lysed by freeze thawing and the lysate was centrifuged for $45 \mathrm{~min}$ at $125,000 \mathrm{~g}, 4^{\circ} \mathrm{C}$ and the supernatant was incubated with $1 \mathrm{ml}$ of glutathione beads (GE healthcare) per 11 of culture for 1-2h. Beads were washed 6x with 25mM HEPES pH7.5, 400mM KCl, 5\% Triton X-100, 10\% glycerol, 4mM DTT, EDTA-free Complete protease inhibitors (Roche) and subsequently with $25 \mathrm{mM}$ HEPES pH7.5, $100 \mathrm{mM} \mathrm{KCl}, 10 \%$ glycerol, $1 \% \mathrm{w} / \mathrm{v}$ OGP, $4 \mathrm{mM}$ DTT. Synaptobrevin was cleaved off the beads with thrombin over night at $4^{\circ} \mathrm{C}$. Thrombin was then inactivated by the addition of $0.1 \mathrm{mM}$ PMSF followed by $1 \mathrm{~h}$ incubation at room temperature. The supernatant was shock frozen and stored at $-80^{\circ} \mathrm{C}$.

The functionality of SNAP25, syntaxin1 and synaptobrevin was monitored by SDSresistant SNARE complex formation (S2) which is show in (Fig. S6).

\section{Reconstitution of membrane fusion}

The tSNARE and vSNARE liposomes were prepared by detergent assisted insertion into preformed liposomes.

tSNARE liposomes: To create a 20mM liposome suspension lipids stored in chloroform were mixed in the following ratio: 25\% phosphatidylserine (PtdSer) (Avanti \#840032), 10\% cholesterol (Sigma), 65\% phosphatidylcholine (PtdChol) (Avanti \#840053). For the experiment shown in Fig. S3 5\% phosphatidyinosotol-4,5bisphosphate $\left(\operatorname{PtdIns}(4,5) \mathrm{P}_{2}\right.$ ) (Avanti \#840046) was used and the amount of PtdChol was correspondingly decreased. Lipids were dried under argon and desiccated for $2 \mathrm{~h}$. Lipids were rehydrated by the addition of $50 \mathrm{mM}$ Tris $\mathrm{pH} 8,150 \mathrm{mM} \mathrm{NaCl}, 2 \mathrm{mM}$ DTT. Lipids were incubated in the buffer for $15 \mathrm{~min}$ at room temperature and subsequently sonicated gently. The liposomes were then passed 9 times though an $800 \mathrm{~nm}$ filter (Whatman). $10 \mu \mathrm{l}$ of the liposomes were then added to $90 \mu \mathrm{l}$ of a $11.1 \mu \mathrm{M}$ tSNARE complex solution and incubated for $15 \mathrm{~min}$ at room temperature. The detergent was then diluted below the critical micelle concentration by the addition of $100 \mu 150 \mathrm{mM}$ Tris $\mathrm{pH} 8,150 \mathrm{mM} \mathrm{NaCl}, 2 \mathrm{mM}$ DTT. The liposomes were then dialyzed over night against 21 of $25 \mathrm{mM}$ HEPES pH7.5, $100 \mathrm{mM} \mathrm{KCl,} \mathrm{5 \%} \mathrm{glycerol,} \mathrm{2mM} \mathrm{DTT,} 10 \mathrm{~g}$ BioBeads (BioRad) at $4^{\circ} \mathrm{C}$ to remove the detergent and spun at $10,000 \mathrm{~g}$ for $5 \mathrm{~min}$ at room temperature to remove aggregates. The supernatant was used for experiments.

vSNARE liposomes: To create a $10 \mathrm{mM}$ liposome suspension lipids stored in chloroform were mixed in the following ratio: 15\% phosphatidylserine (PtdSer) (Avanti \#840032), 10\% cholesterol (Sigma), 72\% phosphatidylcholine (PtdChol) (Avanti \#840053), 1.5\% N-(7-nitro-2-1,3-benzoxadiazol-4-yl)-1,2-dipalmitoyl phosphatidylethanolamine (Invitrogen) and $1.5 \%$ rhodamine- 
phosphatidylethanolamine (Invitrogen), dried under argon and desiccated for $2 \mathrm{~h}$. Lipids were rehydrated by the addition of $50 \mathrm{mM}$ Tris $\mathrm{pH} 8,150 \mathrm{mM} \mathrm{NaCl}, 2 \mathrm{mM}$ DTT. Lipids were incubated in the buffer for $15 \mathrm{~min}$ at room temperature and sonicated gently. The liposomes were then passed 21 times though a $400 \mathrm{~nm}$ filter (Whatman) and subsequently through a $50 \mathrm{~nm}$ filter (Whatman). $20 \mu 1$ of the liposomes were the added to $80 \mu \mathrm{l}$ of a $50 \mu \mathrm{M}$ solution of synaptobrevin and incubated for $15 \mathrm{~min}$ at room temperature. The detergent was then diluted below the critical micelle concentration by the addition of $100 \mu 150 \mathrm{mM}$ Tris $\mathrm{pH} 8,150 \mathrm{mM} \mathrm{NaCl}, 2 \mathrm{mM}$ DTT. The liposomes were then dialyzed over night against 21 of $25 \mathrm{mM}$ HEPES pH7.5, $100 \mathrm{mM} \mathrm{KCl,} 5 \%$ glycerol, $2 \mathrm{mM}$ DTT, $10 \mathrm{~g}$ BioBeads (BioRad) over night at $4^{\circ} \mathrm{C}$ to remove the detergent and spun at $10,000 \mathrm{~g}$ for $5 \mathrm{~min}$ at room temperature to remove aggregates. The supernatant was used for experiments.

The size of the reconstituted t- and vSNARE liposomes was checked by dynamic light scattering. The t- and vSNARE liposomes had an average hydrodynamic radius of 60 70nm and polydispersity index of $0.14-0.17$.

The integrity of both the tSNARE and vSNARE liposomes was checked by negative stain electron microscopy and incubation with Botulinum neurotoxin E or Tetanus toxin. As expected for random integration into liposomes only $50 \%$ of SNAP-25 and synaptobrevin, respectively were cleaved. As analyzed by electron microscopy the tSNARE liposomes contained a significant number of larger liposomes $(>200 \mathrm{~nm})$ as compared to the vSNARE lipsosomes.

For the fusion experiments $75 \mu 1 \mathrm{tSNARE}$ liposomes were mixed with $25 \mu 1 \mathrm{vSNARE}$ liposomes. The syt1 C2A, C2B, C2AB, C2AA, C2BB and syt4 C2AB domains were added at a concentration of $7.5 \mu \mathrm{M}$. The reactions were incubated on ice for $30 \mathrm{~min}$ before measurement. $\mathrm{Ca}^{2+}$ was added immediately before the measurement to final concentration of $500 \mu \mathrm{M}$. Fusion was monitored by dequenching of NBD. The NBD was excited at $465 \mathrm{~nm}$ and emission was detected at $530 \mathrm{~nm}$. After 50 min $10 \%$ Triton X-100 was added to a final concentration of $1 \%$ to determine the maximum fluorescence. Synaptotagmin has been shown to promote full fusion of tSNARE and vSNARE liposomes under these conditions (S3). A slight condensation occurs on the outside of the cuvette on moving to $37^{\circ} \mathrm{C}(\mathrm{t}=0)$ the temperature at which measurements are made. This precludes an accurate measurement of the initial rates.

\section{Co-sedimentation assays}

Liposomes were prepared using either Folch lipids (fraction1, Sigma), 5\% PtdIns(4,5) $\mathrm{P}_{2}$ (Avanti \#840046), 10\% cholesterol (Sigma), 15\% PtdSer (Avanti \#840032), 70\% PtdChol (Avanti \#840053) (Fig. 2A and Fig. S1B), 5\% PtdIns(4,5) $\mathrm{P}_{2}$ (Avanti \#840046), 10\% cholesterol (Sigma), 25\% PtdSer (Avanti \#840032), 60\% PtdChol (Avanti \#840053) (Fig. 2C) or varying amounts of PtdSer, PtdChol and 10\% cholesterol as indicated in Fig. S1A. Lipids were combined, dried under argon, desiccated for $2 \mathrm{~h}$ and buffer was added to a final concentration of $1 \mathrm{mg} / \mathrm{ml}$ liposomes. $0.5 \mathrm{mg} / \mathrm{ml}$ liposomes were incubated with $20 \mu \mathrm{g}$ of the proteins indicated in the figures. $\mathrm{Ca}^{2+}$ and EDTA were added to a final concentration of $1 \mathrm{mM}$. After $30 \mathrm{~min}$ at room temperature the liposomes were centrifuged at $165,000 \mathrm{~g}$ for $10 \mathrm{~min}$ at room temperature. Equal amounts of the supernatants and pellets were loaded. Proteins were subsequently visualized by Coomassie staining after SDS-PAGE. The liposomes shown in Fig. 2A and Fig. 2C were sequentially passed 9x though an 800nm filter, $21 \mathrm{x}$ through a $200 \mathrm{~nm}$ filter, $21 \mathrm{x}$ times through a $100 \mathrm{~nm}$ filter and $21 \mathrm{x}$ trough a $50 \mathrm{~nm}$ filter. The average hydrodynamic diameter of the liposomes shown in Fig. 1B as determined by dynamic light scattering was 290nm (Pdl 0.266) for the 800nm 
liposomes, 124nm (Pdl 0.139) for the 200nm liposomes, 104nm for the $100 \mathrm{~nm}(\mathrm{Pdl}$ $0.086)$ liposomes and 71.9nm ( $\mathrm{Pdl} 0.068)$ for the 50nm liposomes. The average hydrodynamic diameter of the liposomes shown in Fig. 1D as determined by dynamic light scattering was 291nm (Pdl 0.308) for the 800nm liposomes, 156nm (Pdl 0.087) for the 200nm liposomes, $118 \mathrm{~nm}(\mathrm{Pdl} 0.083)$ for the $100 \mathrm{~nm}$ liposomes and $74 \mathrm{~nm}(\mathrm{Pdl}$ 0.042 ) for the $50 \mathrm{~nm}$ liposomes. Pdl indicates the polydispersity index. The actual size of the liposomes is significantly smaller for the 800 and 200 liposomes suggesting that the actual curvature preference of the synaptotagmin $\mathrm{C} 2 \mathrm{AB}$ domain shown in Fig. $1 \mathrm{~B}$ is underestimated. The very similar size of the liposomes shown in Fig. 1B and Fig. 1D shows that the loss of curvature preference for the liposomes shown in Fig. 1D is not attributable to a smaller size of liposomes shown in Fig. 1D.

\section{Liposome tubulation assay by negative stain electron microscopy}

Folch lipids (fraction 1, Sigma) were dried under argon, desiccated for $2 \mathrm{~h}$ and buffer was added to a final concentration of $1 \mathrm{mg} / \mathrm{ml}$ liposomes. $0.3 \mathrm{mg} / \mathrm{ml}$ Folch were incubated with $10 \mu \mathrm{M}$ syt $1 \mathrm{C} 2 \mathrm{~A}, \mathrm{C} 2 \mathrm{~B}$ or $\mathrm{C} 2 \mathrm{AB}$ domain fragments, $10 \mu \mathrm{M}$ syt $3 \mathrm{C} 2 \mathrm{AB}$, $10 \mu \mathrm{M}$ syt9 GST-C2AB or $15 \mu \mathrm{M}$ slp2 C2AB in the presence of $1 \mathrm{mM}$ EDTA or $\mathrm{CaCl}_{2}$ for $1 \mathrm{~h}$ at room temperature and stained with $2 \%$ uranylacetate. Folch liposomes were used because artificial liposomes as used previously (S4) tended to show deformations even in the absence of protein. 


\section{Calculations}

\section{Calculation of the synaptotagmin spontaneous curvature}

To estimate the synaptotagmin spontaneous curvature $J_{s}^{s y t}$ we consider the elastic stresses and strains produced within a fragment of lipid monolayer by insertion of the hydrophobic segments of $\mathrm{C} 2$, and seek for the monolayer shape compensating the effects of these stresses.

We consider an initially flat monolayer fragment of area $A_{0}$ and thickness $L$. An inclusion characterized by an in-plane area $\Delta A$ is embedded into the monolayer fragment up to the depth $d$. As a result of this embedding, the upper part of the monolayer penetrated by the inclusion tends to expand its area up to $A_{0}+\Delta A$, whereas the lower part tends to conserve its initial area $A_{0}$. The created area mismatch between the upper and lower portions of the monolayer fragment and the related elastic energy can be partially compensated by the monolayer bending, which will be characterized by the curvature $J$ of the monolayer bottom surface. We will find the spontaneous curvature $J_{s}$ by looking for the value of $J$ corresponding to the minimal elastic energy of the monolayer fragment.

To describe the position along the monolayer thickness we use the coordinate along the axis $\mathrm{z}$ perpendicular to the monolayer plane and initiating at the monolayer bottom. We consider the monolayer fragment as consisting of infinitesimally thin sublayers of thickness $d z$, each characterized by the area stretching-compression modulus $\lambda(z)$. The elastic energy of each sub-layer is given by

$$
d F=\frac{1}{2} \cdot \lambda(z) \cdot\left[A(z)-A_{S}(z)\right]^{2} d z
$$

where $A(z)$ is actual area of the sub-layer, and $A_{S}(z)$ is the sub-layer spontaneous area corresponding to its unstressed state. The actual area $A(z)$ can be expressed through the area $A$ and the total curvature $J$ (S5) of the bottom monolayer plane by

$$
A(z)=A \cdot(1+z \cdot J)
$$

(the Eq.(A2) relates to cylindrical shape and, therefore, neglects the effects of the Gaussian curvature (S5)).

We assume that the rigidity $\lambda(z)$ has the same value $\lambda_{0}$ everywhere except for a narrow region around the plane $z^{*} \approx \frac{2}{3} L$ of the lipid glycerol backbones, where the rigidity has a considerably higher value. This assumption takes into account that the so called neutral (S6) (or pivotal (S7)) plane of lipid monolayers is always localized close to the plane of the glycerol backbones., To express this assumption mathematically, we present the rigidity by $\lambda(z)=\lambda_{0}+\Lambda \cdot \delta\left(z-z^{*}\right)$, where $\delta\left(z-z^{*}\right)$ is the delta-function.

According to our model, the spontaneous area $A_{S}(z)$ equals $A_{0}+\Delta A$ for the sublayers penetrated by the inclusion and $A_{0}$ for the rest of the sub-layers.

Taking into account the Eqs. (A1), (A2) and the assumptions above, integrating the elastic energy (Eq.A1) over the monolayer thickness and minimizing it with respect to the area $A$ and the curvature $J$ of the bottom monolayer surface, we obtain the following expression for the spontaneous curvature. 


$$
\begin{aligned}
J_{s}= & \frac{\left\{\left(\lambda_{0} L+\Lambda\right) \cdot\left[\frac{1}{2} \lambda_{0} d \cdot(2 L-d)+\Lambda z^{*}\right]-\left(\lambda_{0} d+\Lambda\right)\left(\frac{1}{2} \lambda_{0} L^{2}+\Lambda z^{*}\right)\right\} \cdot \frac{\Delta A}{A_{0}}}{\left[\left(\lambda_{0} L+\Lambda\right)\left(\frac{1}{3} \lambda_{0} L^{3}+\Lambda z^{* 2}\right)-\left(\frac{1}{2} \lambda_{0} L^{2}+\Lambda z^{*}\right)^{2}\right]+} \\
& {\left[\left(\frac{1}{3} \lambda_{0} L^{3}+\Lambda z^{* 2}\right)\left(\lambda_{0} d+\Lambda\right)-\left(\frac{1}{2} \lambda_{0} L^{2}+\Lambda z^{*}\right)\left(\frac{1}{2} \lambda_{0} d(2 L-d)+\Lambda z^{*}\right)\right] \cdot \frac{\Delta A}{A_{0}} }
\end{aligned}
$$

Our approach neglects the energy of transverse shear deformations of the monolayer matrix, which are also generated by the inclusion. This neglecting can be justified only for the case of small inclusions, such as the hydrophobic appendages of $\mathrm{C} 2$ domains (S8), whose in-plane dimensions do not exceed the characteristic decay length of membrane deformations. The latter can be estimated through the lipid monolayer elastic moduli of splay (bending), $\kappa \approx 4 \cdot 10^{-20} \mathrm{~J}$ (see e.g.(S7)), and tilt, $\kappa_{t}$ (S9), as $\sqrt{\kappa / \kappa_{t}} \approx 1 \mathrm{~nm}$ (S9). In this case also the area of the membrane fragment deformed by the insertion will have an area of the order of square of the decay length, i.e. the fragment will constitute of just few lipid molecules. The more general model accounting for the spontaneous curvatures generated by larger inclusions will be published elsewhere.

Eq. (A3) allows us to estimate the spontaneous curvature $J_{s}^{s y t}$ generated by a C2AB domain. According to (S8) a double $\mathrm{C} 2$ domain binds 2 lipid polar heads meaning that $A_{0} \approx 1.4 \mathrm{~nm}^{2}$. Estimations based on the structural data ( $\mathrm{S} 8$ ) shows that after insertion of the hydrophobic appendages, the area of the complex between a double $\mathrm{C} 2$ domain and two lipid molecules becomes $A_{0}+\Delta A=2 \mathrm{~nm}^{2}$, meaning that $\Delta A \approx 0.6 \mathrm{~nm}^{2}$. Finally, the appendage penetrate about a third of the monolayer thickness meaning that $d=\frac{1}{3} L(\mathrm{~S} 8)$. Assuming that $\frac{\Lambda}{\lambda_{0} L}>>1$ (the region around the plane of glycerol backbones is much more rigid than the rest of the monolayer matrix) and inserting the above values into the Eq.(A3) we obtain that the synaptotagmin spontaneous curvature is close to the inverse monolayer thickness, $J_{s}^{s y t} \approx 1 / L \approx 0.7 \mathrm{~nm}^{-1}$.

\section{Estimation of the coverage of membrane surface by syt1 in tubes of $17 \mathrm{~nm}$ diameter}

Based on the determined above value of the synaptotagmin spontaneous curvature $J_{s}^{s y t} \approx 0.7 \mathrm{~nm}^{-1}$, we can estimate the membrane area, which has to be covered by syt 1 in order to stabilize the $17 \mathrm{~nm}$ tubules, which can be characterised by the radius and the curvature of the membrane mid surface equal to $R_{t} \approx 7 \mathrm{~nm}$ and $J_{t}=1 / R_{t} \approx 0.14 \mathrm{~nm}^{-1}$, respectively. The curvature of a stress-free bilayer can be expressed through the spontaneous curvatures of its outer, $J_{s}^{\text {out }}$, and inner, $J_{s}^{\text {in }}$, monolayers by $J_{t}=\left(J_{s}^{\text {out }}-J_{s}^{\text {in }}\right) / 2(\mathrm{~S} 10)$. The spontaneous curvature of the external monolayer containing syt $1, J_{s}^{\text {out }}$, can be presented as $J_{s}^{\text {out }}=J_{s}^{0}+\phi \cdot J_{s}^{\text {syt }}$, where $\phi$ is the monolayer area fraction covered by syt 1 and $J_{s}^{0}$ is the monolayer spontaneous curvature in the absence of synaptotagmin (S11). The spontaneous curvature of the 
inner monolayer, which does not contain synaptotagmin, is $J_{s}^{\text {in }}=J_{s}^{0}$. Taken together the above relationships show that the curvature of the unstressed tubular membrane is $J_{t}=\phi \cdot J_{s}^{s y t} / 2$. Using the above values for $J_{s}^{s y t}$ and $J_{t}$, we obtain $\phi=0.4$, meaning that about $40 \%$ of the tubular surface has to be covered by synaptotagmin.

Estimation of the effect of syt1 induced buckling on the energy barrier for hemifusion

We assume that the forming dimple is similar to the end-caps of the tubules generated by syt 1 in our liposome tubulation experiments, and, therefore the curvature radius of its external surface is about $10 \mathrm{~nm}$. Matching the stalk configuration (S12) to the buckled surface we find the membrane area, which undergoes unbending in the course of stalk formation, and estimate the released energy to be $20 \mathrm{k}_{\mathrm{B}} \mathrm{T}$. This reduces the overall energy of stalk formation from, approximately, $40 \mathrm{k}_{\mathrm{B}} \mathrm{T}(\mathrm{S} 12)$ to about $20 \mathrm{k}_{\mathrm{B}} \mathrm{T}$. 


\section{Supplementary Figures}

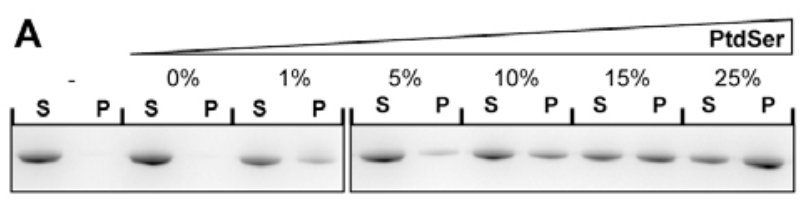

C
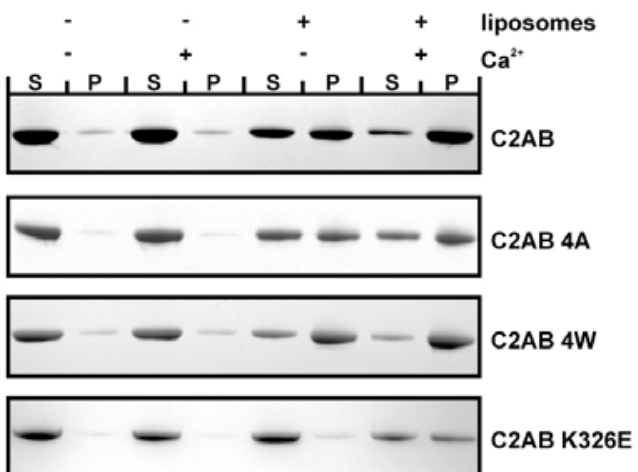

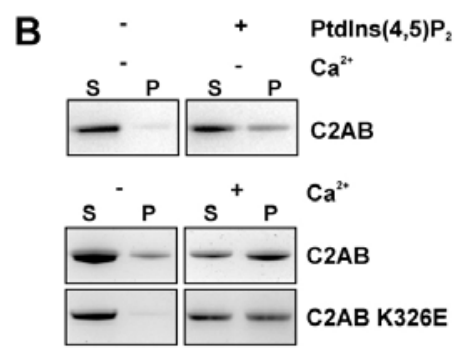

D
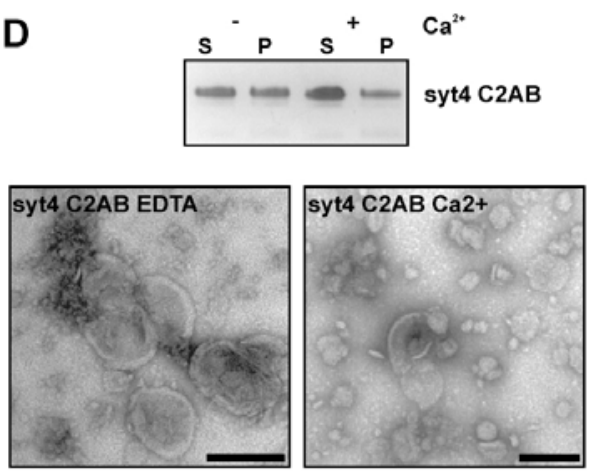

Fig. S1

Characterisation of liposome binding by wild type and mutant syt1.

(A) PtdSer (PS) dependence of lipid binding by syt1 in the presence of $1 \mathrm{mM} \mathrm{Ca}^{2+}$ determined by liposome co-sedimentation assays. The numbers above the gels indicate the PtdSer content in the liposomes. These liposomes contained no $\operatorname{Ptd} \operatorname{lns}(4,5) \mathrm{P}_{2}$. (B) $\mathrm{Ca}^{2+}$-independent binding to liposomes can be mediated by $\mathrm{Ptd} \operatorname{lns}(4,5) \mathrm{P}_{2}$ as determined by lipid cosedimentation. $\mathrm{Ca}^{2+}$-independent $\mathrm{Ptd} \operatorname{lns}(4,5) \mathrm{P}_{2}$ binding was abolished by the $\mathrm{K} 326 \mathrm{E}$ mutation. The liposomes in the upper panel contained either no Ptdlns $(4,5) \mathrm{P}_{2}$ or $5 \%$ Ptdlns $(4,5) \mathrm{P}_{2}$ respectively. The liposomes in the lower panel contained $5 \% \operatorname{Ptdlns}(4,5) \mathrm{P}_{2}$ and $15 \%$ PtdSer. (C) Co-sedimentation assay using Folch liposomes and the indicated proteins. $\mathrm{Ca}^{2+}$ was added to a final concentration of $1 \mathrm{mM}$. (D) Lipid co-sedimentation and electron micrographs showing liposome tubulation of Folch liposomes incubated with the syt4 C2AB domain. $\mathrm{Ca}^{2+}$ was added to a final concentration of $1 \mathrm{mM}$. All liposomes shown in Fig. $\mathrm{S} 1$ were extruded through an $800 \mathrm{~nm}$ filter. 

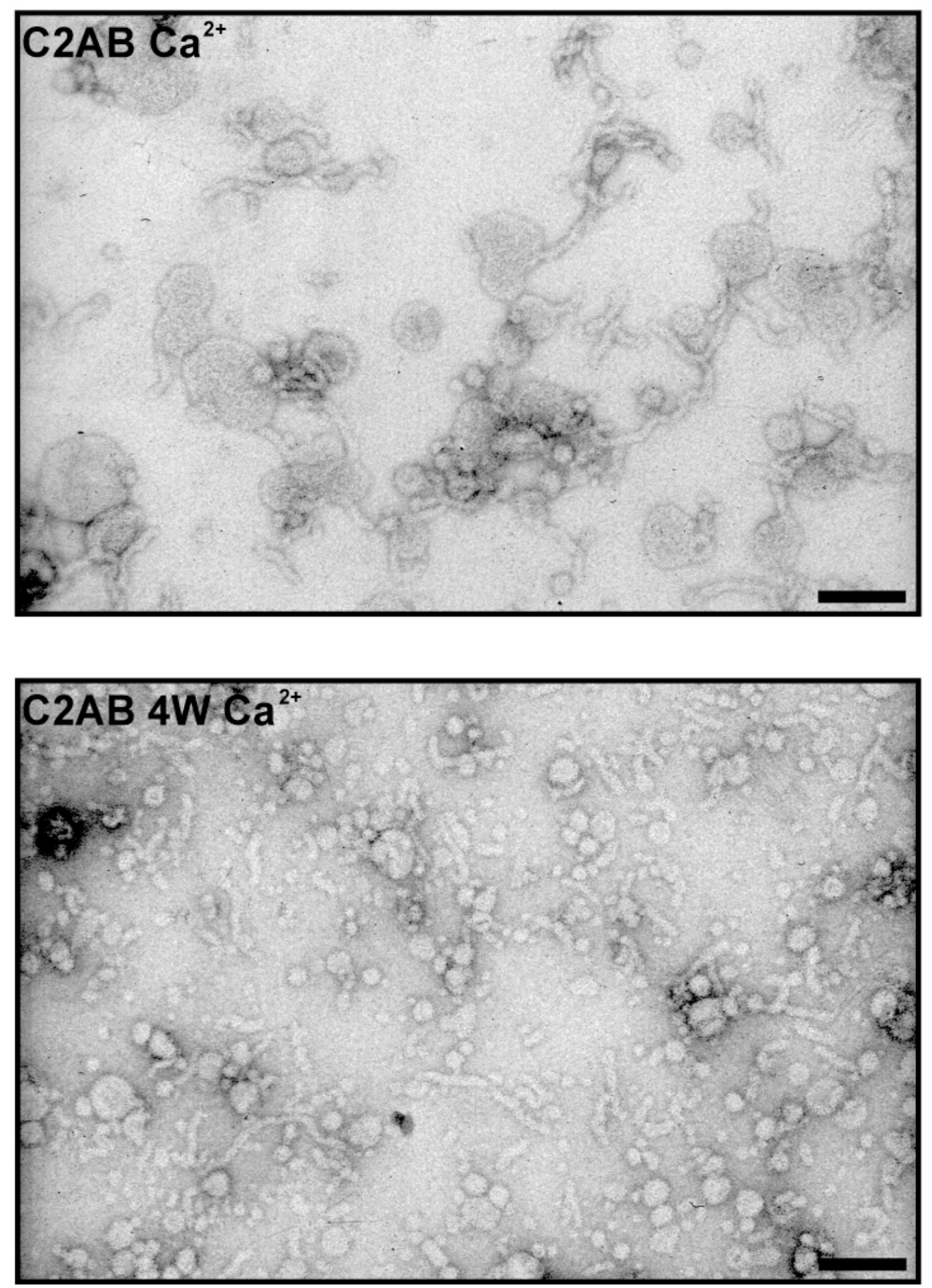

Fig. S2

Enhanced vesiculation of Folch liposomes by the $4 \mathrm{~W}$ mutant.

Electron micrographs of Folch liposomes incubated with $10 \mu \mathrm{M}$ of the indicated proteins. Scale bar: $100 \mathrm{~nm}$. 


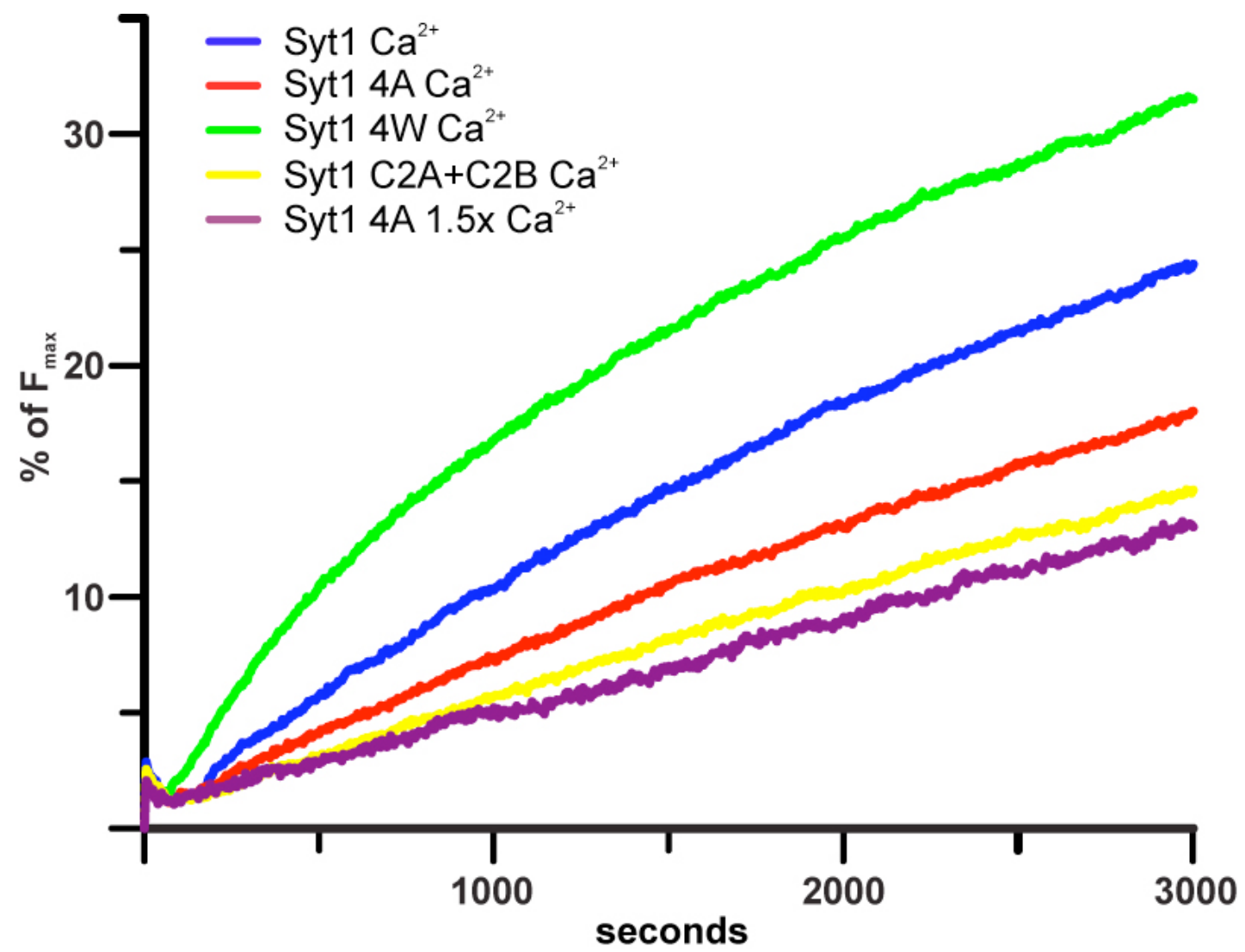

Fig. S3

Promotion of SNARE-mediated membrane fusion in vitro by wild type and mutant syt1. In vitro membrane fusion assay as described in the Material and Methods using the indicated proteins at a concentration of $7.5 \mu \mathrm{M}$. $1.5 \mathrm{x}$ syt4A was used at a concentration of $11.25 \mu \mathrm{M}$. All experiments were conducted in the presence of $500 \mu \mathrm{M} \mathrm{Ca}^{2+}$. 


\section{i) docked stage}
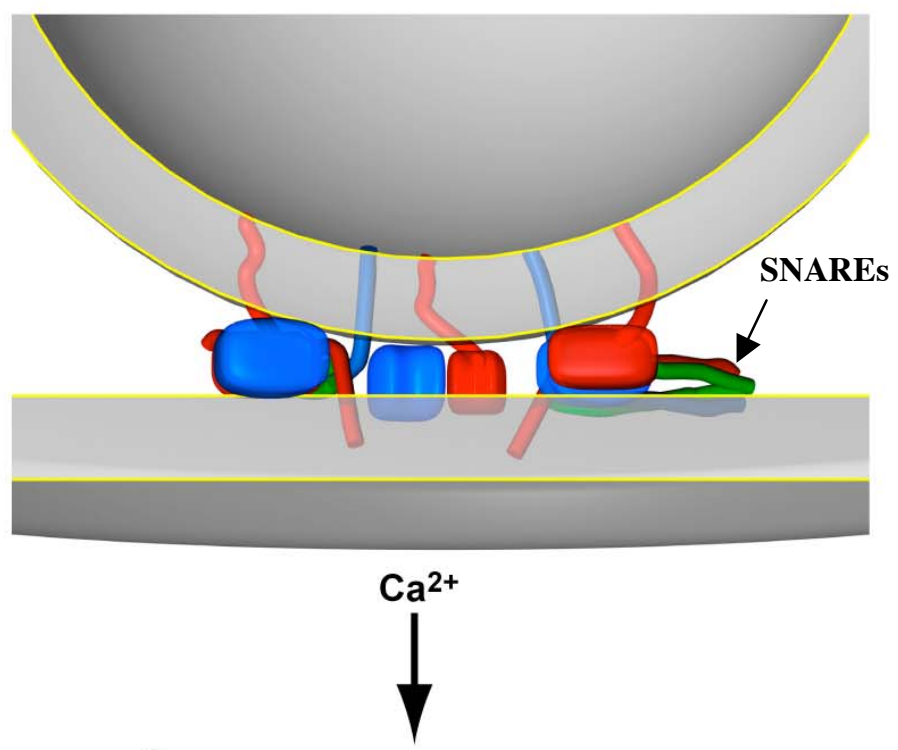

ii) $\mathrm{Ca}^{2+}$-induced buckling

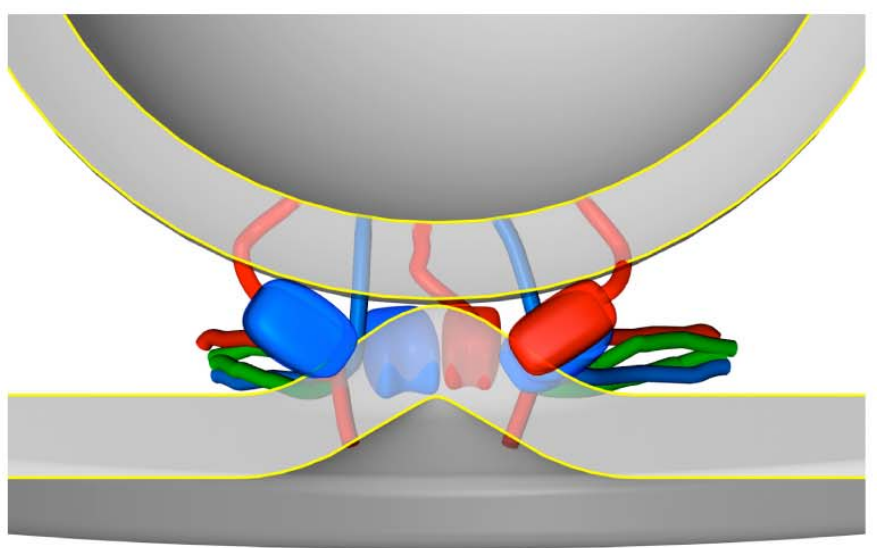

\section{iii) hemifusion stage}

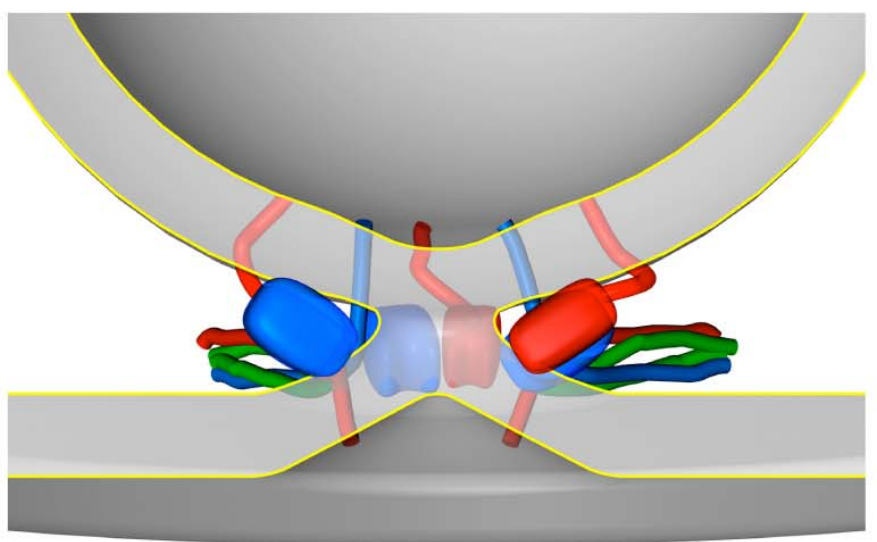

Fig. 54

Model for the function of syt 1 during $\mathrm{Ca}^{2+}$. induced membrane fusion of synaptic vesicles.

(i) Prior to the $\mathrm{Ca}^{2+}$ trigger, synaptic vesicles are docked and primed for release and the SNARE bundle is already partially assembled holding the two membranes about 3-4 nm apart. In this state syt1 (C2 domains shown as blue and red ovals, the syt1 transmembrane domain is shown in red and the intra-lumenal domain of syt1 is omitted) may interact in a $\mathrm{Ca}^{2+}$ independent manner with the SNARE complex and possibly with plasma membrane Ptdlns $(4,5) \mathrm{P}_{2}$. (ii) Upon $\mathrm{Ca}^{2+}$ influx, syt1 changes its orientation and inserts the loops surrounding the $\mathrm{Ca}^{2+}$ binding pockets into the plasma membrane. The insertion works like a wedge in the membrane leaflet and as a result the plasma membrane is buckled towards the vesicle which is held in place by the SNARE complex. (iii) This will induce curvature stress in the plasma membrane and a closer proximity of the two membranes thus leading to dramatically increased hemifusion fusion probability, leading to full fusion and thus exocytosis. 

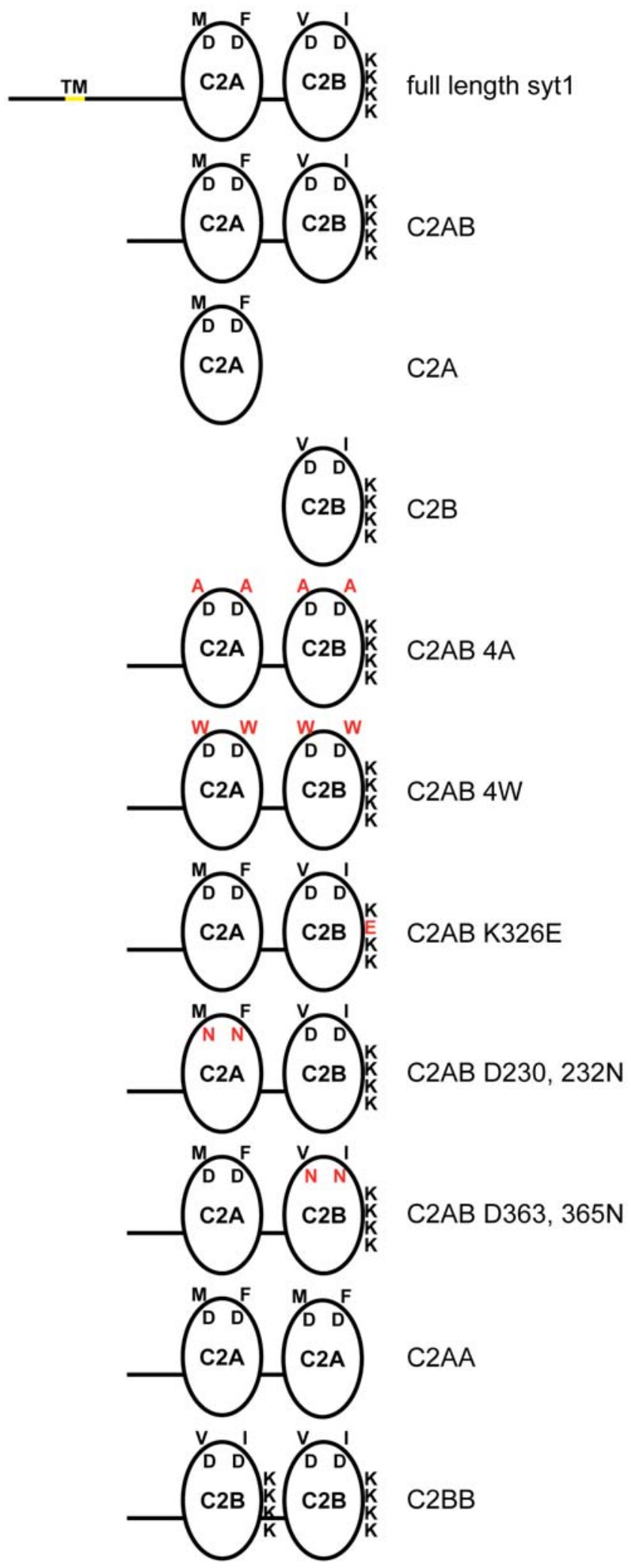

Fig. S5

A list of all syt1 fragments and mutants used in this study.

For details of their construction refer to the Material and Methods. 


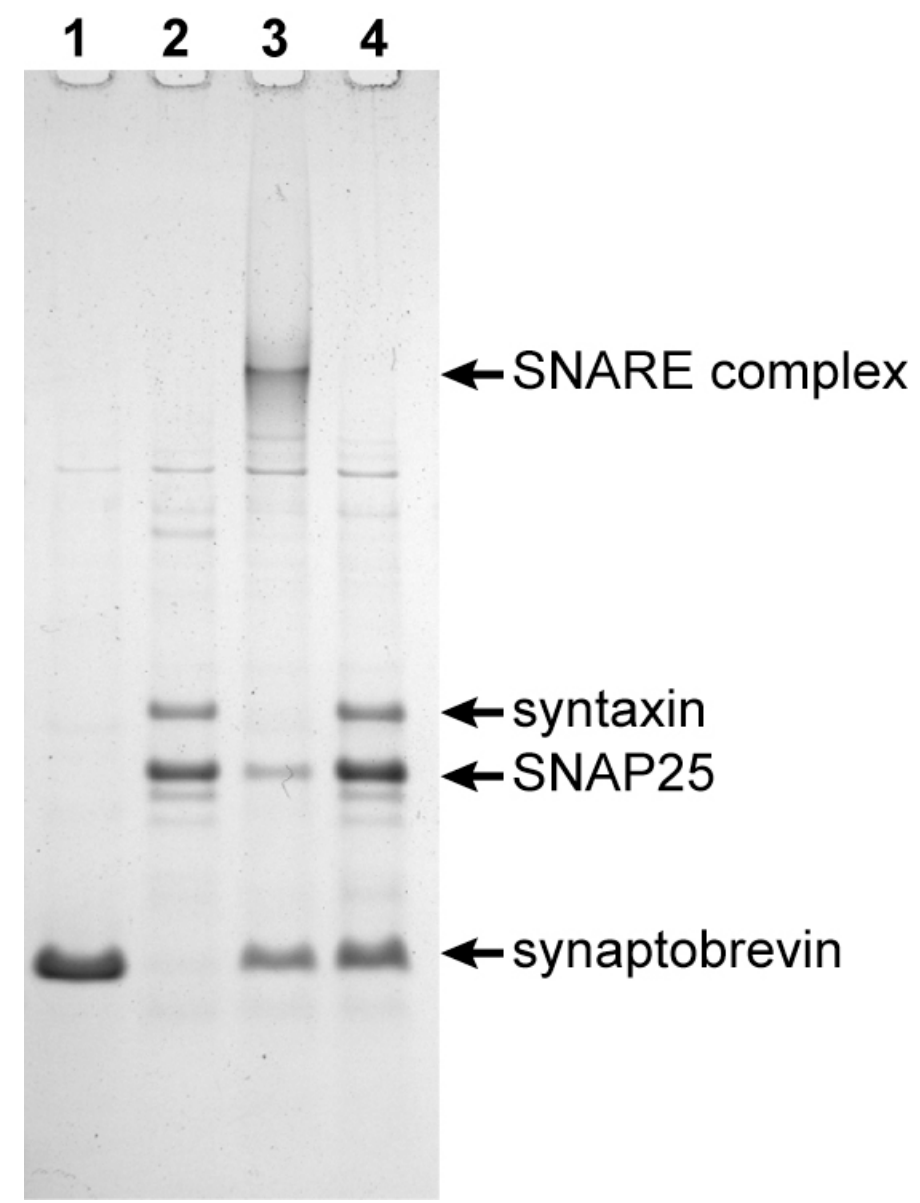

Fig. 56

Coomassie stained SDS-PAGE gel showing the functionality of the full length SNARE molecules used in this study.

For detail of their construction and purification refer to the Material and Methods. 1. synaptobrevin. 2. tSNARE complex. 3. synaptobrevin + tSNARE complex incubated for 30 minutes at $37^{\circ} \mathrm{C}$. 4. synaptobrevin + tSNARE complex incubated for 30 minutes at $37^{\circ} \mathrm{C}$ and subsequently boiled for 5 minutes. 


\section{$\underline{\text { References }}$}

S1. C. Rickman, M. Craxton, S. Osborne, B. Davletov, Biochem. J. 378, 681 (2004).

S2. T. Hayashi et al., Embo J 13, 5051 (1994).

S3. A. Bhalla, M. C. Chicka, W. C. Tucker, E. R. Chapman, Nat. Struct. Mol. Biol. 13, 323 (2006).

S4. D. Arac et al., Nat. Struct. Mol. Biol. 13, 209 (2006).

S5. M. Spivak, A Comprehensive introduction to differential feometry (Brandeis University, 1970), pp.

S6. $\quad$ M. M. Kozlov, M. Winterhalter, J. Phys.II France 1, 1085 (1991).

S7. $\quad$ S. Leikin, M. M. Kozlov, N. L. Fuller, R. P. Rand, Biophys. J. 71, 2623 (1996).

S8. D. Z. Herrick, S. Sterbling, K. A. Rasch, A. Hinderliter, D. S. Cafiso, Biochemistry 45, 9668 (2006).

S9. $\quad$ M. Hamm, M. Kozlov, European Physical J. B 6, 519 (1998).

S10. L. V. Chernomordik, M. M. Kozlov, Annu. Rev. Biochem. 72, 175 (2003).

S11. M. M. Kozlov, W. Helfrich, Langmuir 8, 2792 (1992).

S12. Y. Kozlovsky, M. M. Kozlov, Biophys. J. 82, 882 (2002). 